\section{In vitro bactericidal activities of various extracts of saffron (Crocus sativus L.) stigmas from Torbat-e Heydarieh, Gonabad and Khorasan, Iran}

\author{
Beniamino T. Cenci-Goga, ${ }^{1}$ \\ Renzo Torricelli, ${ }^{2}$ \\ Yousef Hosseinzadeh Gonabad, ${ }^{2}$ \\ Nicoletta Ferradini, ${ }^{2}$ \\ Roberto Venanzoni, ${ }^{3}$ Paola Sechi, \\ Maria Francesca Iulietto, \\ Emidio Albertini ${ }^{2}$
}

${ }^{1}$ Department of Veterinary Medicine;

${ }^{2}$ Department of Agricultural, Food and

Environmental Sciences; ${ }^{3}$ Department of

Chemistry, Biology and Biotechnology,

University of Perugia, Perugia, Italy

\begin{abstract}
Saffron is one of the most expensive spices in the world $(20,000 € / \mathrm{kg})$ and this is due not only to the high demand for its various uses such as cooking, production of staining medicines, cosmetics etc., but also for the high costs of cultivation and production. Several studies have demonstrated that differences in saffron quality are mainly due to the methodology followed in the processing of stigmas, and environmental conditions independent of the origin. Some authors found phenotypic variations within cultivated saffron, but very limited genetic diversity. The reason for the very limited genetic diversity in cultivated saffron is explained by its asexual mode of reproduction (propagation). The aim of this study was to assess the antimicrobial activity of stigma saffron, which were tested against different bacteria strains. The results obtained from the antimicrobial activity study indicate that stigmas of $C$. sativus have some antimicrobial effect.
\end{abstract}

\section{Introduction}

Crocus sativus L. (saffron) belongs to the Iridaceae (Liliales, Monocots) family, it is a sterile triploid $(2 \mathrm{n}=3 \mathrm{x}=24)$ species that is propagated vegetatively via its corms which undergo a period of dormancy. ${ }^{1}$ At least 85 species are known to belong to the Crocus genus and $C$. sativus is the most interesting one, not only as source of spice for cooking but also as basic compound in cosmetics and medicine. Several archeological studies locate the probable saffron centre of origin in Iran and Kashmir even if, recently, some authors have identified Crete as the primary centre of domestication during the Late Bronze Age. ${ }^{2-5}$ In fact, even though the botanical origins of $C$. sativus have not yet been completely clarified, some authors have identified $C$. cartwrightianus $(2 \mathrm{n}=16)$, which grows in the southern Greece and in the neighbouring islands, and $C$. oreocreticus (ibid.), which grows in Crete, as putative fertile diploid progenitors. ${ }^{6}$ Saffron was introduced in to the Greek and Roman world by Phoenicians and later Arabs and Moors brought it to Spain.2,5,7 Many Greek, Roman and Egyptian historians, described the use of saffron as a precious component to stain cloth, to enrich the taste of food and drinks and for use in medical therapy. ${ }^{6,8,9}$ The pharmacological effects of saffron components such as safranal and crocin are well known and widely used in medicine. Several studies on the biological activities of these constituents have highlighted the beneficial therapeutic effects and are often used to support traditional medical therapies in various diseases. ${ }^{10}$ Crocin, and safranal have displayed important antioxidant properties that prevent gastric disorders like ulcer formation and stomach lesion. ${ }^{11,12}$ These compounds are also used to prevent cardiovascular disease, insulin resistance, depression, premenstrual syndrome, insomnia and anxiety. ${ }^{13-21}$ Studies on the antimicrobial properties of saffron active compounds are few, several authors have been reported the anti-bacterial activity of aqueous and methanolic extracts of crocin and safranal against Helicobacter pylori. ${ }^{22,23}$ An interesting anti-bacterial effects of the same active compounds on stigma contamination by Salmonella during storage at room temperature was observed. ${ }^{24}$ The absence of Salmonella on saffron spice coming from the main producer countries (Greece, Iran, Italy, Morocco, and Spain) has also been observed. ${ }^{25}$

Despite the high production costs, saffron cultivation is widespread throughout the world and it is currently cultivated not only in Anatolia but also in China, India, Turkey, Europe, Africa and more recently in Mexico and Australia. ${ }^{26}$

Total world saffron production is estimated at about 220,000 tons, of which about $90 \%$ is produced in Iran (Khorasan Province) and the rest in Greece, Spain, Italy and India (Kashmir). ${ }^{27-29}$ The components of the spice saffron are localized in the red stigmatic lobes of $C$. sativus flower and these are responsible for its distinct color, flavor and smell. ${ }^{30}$ The commercial spice is obtained from dried stigmas and marketed as saffron filaments or as powder from milled stigmas. Saffron is one of the
Correspondence: Beniamino T. Cenci-Goga, Department of Veterinary Medicine, University of Perugia, via San Costanzo, 06126 Perugia, Italy

E-mail: beniamino.cencigoga@unipg.it

Key words: Saffron; Antimicrobial activity; Enterococcus spp.; Staphylococcus spp.; Escherichia coli.

Contributions: the authors contributed equally.

Conflict of interest: the authors declare no potential conflict of interest.

Funding: none.

Received for publication: 17 January 2018.

Revision received: 26 January 2018

Accepted for publication: 26 January 2018.

This work is licensed under a Creative Commons Attribution NonCommercial 4.0 License (CC BY-NC 4.0).

(C) Copyright B.T. Cenci-Gogaet al., 2018

Licensee PAGEPress, Italy

Microbiology Research 2018; 9:7583

doi:10.4081/mr.2018.7583

most expensive spices in the world $(20,000$ $€ / \mathrm{kg}$ ), ${ }^{31}$ and this is due not only to the of the high demand for its various uses such as cooking, or for the production of staining medicines, cosmetics, etc. ${ }^{7}$ but also for the high costs of cultivation and production. In order to gather the saffron, stigmas of the $C$. sativus flowers must be handpicked. This is time consuming; usually to obtain 1 gram of saffron, an average of 150 flowers must be collected. ${ }^{32}$

Many researches have demonstrated that differences in saffron quality are mainly due to the methodology used in the processing stigmas and, independent from the origin of the species quality is also influenced by sowing time and environmental conditions. ${ }^{33-35}$ Several studies have found phenotypic variations within cultivated saffron, such as flower size, shape of the tepals, differences of colour and intensity in the tepals of samples collected from different areas, but very limited genetic diversity has been observed. ${ }^{34,36-38}$

The very reduced genetic diversity existent in cultivated saffron is attributed to its asexual propagation, and by successive selection during breeding. ${ }^{36}$ However, other factors that may have contributed to the low level of molecular polymorphisms found are related to the marker techniques that have been applied. ${ }^{39,40}$

In an attempt to determine possible antimicrobial properties of saffron, the aim of this study was to assess the antimicrobial 
activity of saffron stigma, which was tested against different bacterial strains.

\section{Materials and Methods}

\section{Plant material}

Iranian ( 6 accessions) and Italian corms ( 2 accessions) were planted in September 2012 on a sandy-clay soil in Umbria, Central Italy $(220 \mathrm{~m}$ a.s.1.). Sowing was executed in raised beds at $20 \mathrm{~cm}$ depth 50 $\mathrm{cm}$ between rows and $20 \mathrm{~cm}$ between corms in rows. A complete randomized block design with two replicates was adopted. Fifteen corms per accession per replication were used; no fertilizer and no irrigation were applied. Weeds were managed by hand.

For antimicrobial activity, stigmas of $C$. sativus collected from Torbat-e Heydarieh (Iran) (sample "A"), Gonabad (sample "B") and Khorasan (sample "C"), dried with the traditional technique of flow of hot air emitted from a ventilated oven were used. Water-washed stigmas were shade dried at room temperature and powdered by manual blender. $1 \mathrm{~g}$ of each of the dried and powdered materials were macerated separately with sterile water at a concentration of 100 $\mathrm{mg} / 100 \mathrm{ml}$.

The bacterial strains used for the test were taken from the collection of the Laboratorio di Ispezione degli Alimenti di Origine Animale (University of Perugia: Escherichia coli, strain CSH26 K-12; Enterococcus faecalis, strain NCTC 12201; and Staphylococcus aureus, strain 27R. The microorganisms were grown aerobically in Nutrient Broth (NB; CM0001, Oxoid, Basingstoke, UK) at $37{ }^{\circ} \mathrm{C}$ for $24 \mathrm{~h}$. The total viable cell count on Nutrient Agar (NA; CM0003, incubated at $37^{\circ} \mathrm{C}$ on air for $24 \mathrm{~h}$; Oxoid) at $24 \mathrm{~h}$ was approximately $10^{9}$ cfu $\mathrm{ml}^{-1}$. Decimal dilutions were performed to obtain the following concentrations in $\mathrm{NB}$ : $10^{6} \mathrm{cfu} \mathrm{m}^{-1}, 10^{5} \mathrm{cfu} \mathrm{ml}^{-1}, 10^{4} \mathrm{cfu} \mathrm{ml}^{-1}$, and $10^{3} \mathrm{cfu} \mathrm{ml}^{-1}$. The total viable cell counts for all dilutions were recorded as controls on NA and on the following media. Violet red bile glucose agar (CM0485, Oxoid), was used for counts of $E$. coli, Enterococcus agar (CM0984, Oxoid) was used for E. faecalis, Oxacillin Resistance Screening Agar base (ORSAB; CM1008, Oxoid) with ORSAB selective supplement (SR019, Oxoid) was used for $S$. aureus.

\section{Antimicrobial screening with a mod- ified well plate test}

Antimicrobial activity was determined using a modified well plate method. ${ }^{41}$ Muller Hinton agar (Oxoid, Basingstoke,
UK) was used for the growth of bacterial strains. Each organism was separately suspended in a normal saline solution and transmittance (T) of $75-77 \%$ at $530 \mathrm{~nm}$ was made, which is equal to $10^{6} \mathrm{cfu} \mathrm{ml}^{-1}$. Each plate was inoculated with $0.2 \mathrm{ml}$ of microbial suspension. $100 \mu 1$ of "A", "B", and "C" sample extracts, respectively, were added to each well and incubated at $37{ }^{\circ} \mathrm{C}$ for $24 \mathrm{~h}$. The positive antimicrobial activity was evaluated based on growth inhibition zone and compared with the control. The extracts were then diluted in a two-fold manner to make different concentrations. $100 \mu$ of the active extracts were then added to each well. All the tests were repeated in duplicates.

\section{Vitality reduction}

Vitality reduction activity was performed for $E$. coli, strain CSH26 K-12; E. faecalis, strain NCTC 12201; and S. aureus, strain 27R, using the BS EN 1040:2005. ${ }^{42}$ Experimental conditions were validated as follows: $1 \mathrm{ml}$ of sterile water and $1 \mathrm{ml}$ of bacterial validation suspension containing $3.010^{2}$ to $1.610^{3} \mathrm{cfu} \mathrm{ml}^{-1}$ were placed in a test tube. The components were left in contact for 2 minutes; then $8 \mathrm{ml}$ of water were added and left in contact at the temperature adopted during the assay for the longest period to be tested (see below). At the end of the contact time, the mixture was vortexstirred and a double count was performed by inclusion in agar. The number of colonyforming units per $\mathrm{ml}$ of the mixture was determined following incubation for 48 hours at $37 \pm 1{ }^{\circ} \mathrm{C}$. The bacterial suspension showing concentrations in a $1.510^{5}$ to $510^{5}$ cfu $\mathrm{ml}^{-1}$ range were diluted up to $10^{6}$ and $10^{7}$. A double counting through inclusion in agar was performed. The number of colonyforming units per $\mathrm{ml}$ of the suspension was determined following incubation for 48 hours at $37 \pm 1^{\circ} \mathrm{C}$. For the assay, the bacterial suspension showing concentrations in a $1.5 \times 10^{8}$ to $5 \times 10^{8} \mathrm{cfu} \mathrm{ml}^{-1}$ range were diluted up to $10^{6}$ and $10^{7}$.

A double counting through inclusion in agar was performed. The number of colonyforming units per $\mathrm{ml}$ of the suspension was determined following incubation for 48 hours at $37^{\circ} \mathrm{C} \pm 1{ }^{\circ} \mathrm{C}$ and $\mathrm{N}$ value was calculated.

The assay sample and the bacterial suspensions had previously been stabilised at the test temperature of $20^{\circ} \mathrm{C} \pm 1^{\circ} \mathrm{C}$. For each bacterial strain and for each concentration of the test substance, one test tube containing $1 \mathrm{ml}$ of sterile water and $1 \mathrm{ml}$ of bacterial test suspension showing concentrations in a $1.5 \times 10^{8}$ to $5 \times 10^{8}$ cfu range, was prepared at the temperature adopted during the assay. Alter 2 minutes of contact, $8 \mathrm{ml}$ of the sample extracts "A", "B", and "C" respectively, were added and left in contact again for the selected times at the test temperature. At the end of the contact time (5 minutes), $1 \mathrm{ml}$ of mixture was transferred into a test tube containing $8 \mathrm{ml}$ of distilled water. After 5 minutes of neutralization procedure, the mixture was vortex-stirred and a double count was performed by inclusion in agar.

The number of cfu per plate was determined following incubation for 48 hours at $37^{\circ} \mathrm{C}$, and $\mathrm{Na}$ value was then calculated.

\section{Statistical data analysis}

For antimicrobial activity, the count was performed using the number of colonies counted on both plates. Only the plates showing a number of colonies included in a 15-300 range were used to perform the result calculation. A deviation of $10 \%$ is accepted, so the limits are 14 and 330. In the assay, where the number of cfu on every plate counted is $<14$, the number of $\mathrm{cfu} / \mathrm{ml}$ was recorded as $<1.410^{2}$. Where the number of cfu on every plate counted was $>330$, the number of $\mathrm{cfu} / \mathrm{ml}$ was recorded as $>3.3$ $10^{3}$.

Vitality reduction is expressed in logarithm and was calculated for each organism and test concentration using the following formulas:

$\mathrm{N}(\mathrm{cfu} / \mathrm{ml})=\mathrm{c} /\left(\mathrm{n}_{1}+0.1 \mathrm{n}_{2}\right) \mathrm{d}$

where $\mathrm{N}=$ bacterial counting; $\mathrm{c}=$ sum of colonies counted on both plates; $\mathrm{n}_{1}=$ number of counted plates in the lower dilution; $\mathrm{n}_{2}=$ number of counted plates in the higher dilution; $d=$ dilution factor corresponding to the lower dilution.

$1 \mathrm{gR}=1 \mathrm{gN}_{0}-1 \mathrm{gNa}$

where: $\mathrm{R}=$ Reduction of vitality; $\mathrm{N}_{0}=$ $\mathrm{N} / 10 ; \mathrm{Na}=$ bacterial counting for the test mixture al the end of the contact time. The higher the value, the higher the vitality reduction.

\section{Results}

For the initial antimicrobial screening with the well plate test (Table 1), S. aureus growth was inhibited by plant extract $A$ and $\mathrm{B}$ at the concentration of $1: 1$ and $1: 2 ;$ E. faecalis growth was inhibited by extract $\mathrm{A}$ and $\mathrm{B}$ at the highest concentration. No activity was detected against $E$. coli and plant extract $\mathrm{C}$ had no detectable antimicrobial activity.

Based on the results of antimicrobial screening, the three tester strains were chal- 
Table 1. Minimum inhibitory concentration of aqueous extract of saffron stigmas (C. sativus from Torbat-e Heydarieh (sample "A"), Gonabad (sample "B") and Khorasan (sample "C"), Iran.

\begin{tabular}{|c|c|c|c|c|c|c|c|c|c|c|c|c|c|c|c|c|c|c|}
\hline & \multicolumn{5}{|c|}{ Sample A } & \multicolumn{7}{|c|}{ Sample B } & \multicolumn{6}{|c|}{ Sample C } \\
\hline & 1 & 2 & 4 & 8 & 16 & C & 1 & 2 & 4 & 8 & 16 & C & 1 & 2 & 4 & 8 & 16 & C \\
\hline E. coli & + & + & + & + & + & + & + & + & + & + & + & + & + & + & + & + & + & + \\
\hline S. aureus & - & - & + & + & + & + & - & - & + & + & + & + & + & + & + & + & + & + \\
\hline E. faecalis & - & + & + & + & + & + & - & + & + & + & + & + & + & + & + & + & + & + \\
\hline
\end{tabular}

MIC: minimum inhibitory concentration. $1=100 \mathrm{mg} / 100 \mathrm{~mL}, 2,4,8,16$ are the serial dilutions, C: negative control.

Table 2. Vitality reduction expressed in logarithm $(\log R)$, for the three tester strains challenged with several dilution of aqueous extract of saffron stigmas (C. sativus from Torbate Heydarieh, Iran).

\begin{tabular}{llllll} 
& Whole & $1: 2$ & $1: 4$ & $1: 8$ & $1: 16$ \\
E. coli & 6.56 & 3.76 & 0.46 & 0.79 & 0.83 \\
E. faecalis & 6.85 & 5.92 & 1.40 & 0.71 & 0.71 \\
\hline S. aureus & 4.44 & 2.47 & 3.83 & 0.77 & 0.77 \\
\hline
\end{tabular}

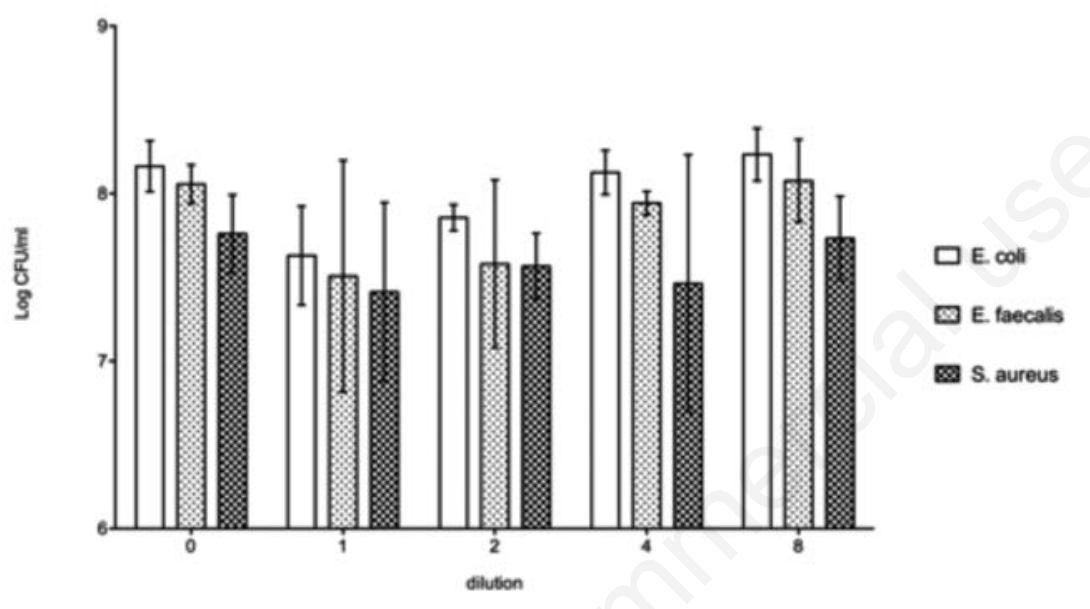

Figure 1. Vitality reduction activity of aqueous extract of saffron stigmas (C. sativus from Torbat-e Heydarieh, Iran).

lenged with aqueous solutions of saffron stigmas, which showed modest, yet evident, antibacterial activities as demonstrated by the test tube analysis. $\mathrm{R}$ values for the highest concentration are in the range 4.4-6.84 (Table 2 and Figure 1).

\section{Discussion and Conclusions}

The results obtained from the antimicrobial activity study indicate that stigmas of $C$. sativus are a good source of antimicrobial agents. Based on these results, it is possible to conclude that aqueous extracts of stigmas of saffron had a moderate antimicrobial activity. These results might be considered sufficient for further studies on the isolation and identification of the active principles and to evaluate of possible synergism among extract components for their antimicrobial activity. In conclusion, the degree of antibacterial property for aqueous extracts of saffron, yet mild, has been demonstrated. Saffron may be selected for use as potential anti-microbial agent in various food products depending on the desired flavour of the products. However, there are some limitations in using saffron in certain food matrix, such as the decreasing of antimicrobial activity when diluted and the strong flavour. The overall flavour of the products may not be acceptable if a large amount of saffron is needed to achieve a significant inhibition of pathogens and hygiene indicators, especially when the effect of other preservatives is weak. A possible way is to use saffron in combination with other preservatives such as acid, salt, sugar, and other chemical preservatives, or other food preservation systems such as thermal processing, freezing or cold storage. ${ }^{43}$

\section{References}

1. Fernández J. Biology, biotechnology and biomedicine of saffron. Recent Res Develop Plant Sci 2004;2:127-65.

2. Alberini M. Saffron: sapore e colore. Lo zafferano. Proceedings of the International Conference on Saffron (Crocus sativus L). L'Aquila, Italy; 1990;39-46.

3. Frello S, Heslop-Harrison J. Repetitive DNA sequences in Crocus vernus Hill (Iridaceae): the genomic organization and distribution of dispersed elements in the genus Crocus and its allies. Genome 2000;43:902-9.

4. Grilli Caiola M, Canini A. Ultrastructure of chromoplasts and other plastids in Crocus sativus L. (Iridaceae). Plant Biosyst 2004;138:4352.

5. Winterhalter P, Straubinger M. Saffronrenewed interest in an ancient spice. Food Rev Int 2000;6:39-59.

6. Basker D, Negbi M. Uses of saffron. Econ Bot 1983;37:228-36.

7. Grilli Caiola M, Canini A. Looking for saffron's (Crocus sativus L.) parents In: Saffron (A.M. Husaini, ed.). Funct Plant Sci Biotechnol 2010;4:1-14.

8. Porter R. The flora of the Theran wall painting: living plants and motifs- Sea lily, Crocus, Iris e Ivy. In: The wall paintings of thera. Proceedings of the first- International Symposium, Thera Foundation. Vol II. 2000;603-630.

9. Tammaro F. Notizie storico-colturali sullo zafferano (Crocus sativus L. Iridaceae) nell'area mediterranea. Micol Veget Medit 1987;2:44-59.

10. Melnyk J, Wang S, Marcone M. Chemical and biological properties of the world's most expensive spice: Saffron. Food Res Int 2010;43:1981-9.

11. Inoue E, Shimizu Y, Shoji M, et al. Pharmacological properties of N-095, a drug containing red ginseng, polygala root, saffron, antelope horn and aloe wood. Am J Chin Med 2005;33:49-60.

12. Xu G, Li G, Ma H, et al. Preventive effect of crocin in inflamed animals and in LPS-challenged RAW 264.7 cells. J Agric Food Chem 2009;57:8325-30. 
13. Agha-Hosseini M, Kashani L, Aleyaseen A, et al. Crocus sativus L. (saffron) in the treatment of premenstrual syndrome: A double-blind, randomised and placebo-controlled trial. BJOG Int $\mathrm{J}$ Obstetr Gynaecol 2008;115:515-9.

14. Gismondi A, Serio M, Canuti L, Canini A. Biochemical, Antioxidant and Antineoplastic Properties of Italian Saffron (Crocus sativus L.). Am J Plant Sci 2012;3:1573-80.

15. He S, Qian Z, Tang F, et al. Effect of crocin on experimental atherosclerosis in quails and its mechanisms. Life Sci 2005;77:907-21.

16. He S, Qian Z, Wen N, et al. Influence of crocetin on experimental atherosclerosis in hyperlipidemic-diet quails. Eur J Pharmacol 2007;554:191-5.

17. Mashmoul M, Azlan A, Khaza'ai H, et al. Saffron: A natural potent antioxidant as a promising anti-obesity drug. Antioxidants 2013;2:293-308.

18. Moshiri E, Akhondzadeh Basti A, Noorbala A, et al. Crocus sativus L. (petal) in the treatment of mild-tomoderate depression: A double-blind, randomized and placebo-controlled trial. Phytomedicine 2006;13:607-11.

19. Pitsikas N, Boultadakis A, Georgiadou $\mathrm{G}$, et al. Effects of the active constituents of Crocus sativus L., crocins, in animal model ofanxiety. Phytomedicine 2008;15:1135-9.

20. Xi L, Qian Z, Xu G, et al. Beneficial impact of crocetin, a carotenoid from saffron, on insulin sensitivity in fructose-fed rats. J Nutr Biochem 2007; 18:64-72.

21. Bukhari SI, Manzoor M, Dhar MK. A comprehensive review of the pharmacological potential of Crocus sativus and its bioactive apocarotenoids. Biomed Pharmacother 2018; 98:733-45.

22. De Monte C, Bizzarri B, Gidaro MC, et al. Bioactive compounds of Crocus sativus L. and their semi-synthetic derivatives as promising antiHelicobacter pylori, anti-malarial and anti-leishmanial agents. J Enzyme Inhib Medic Chem 2015;30:1027-33

23. Nakhaei M, Khaje-Karamoddin M, Ramezani M. Inhibition of Helicobacter pylori growth in vitro by Saffron (Crocus sativus L.). Iran J Basic Med Sci 2008;11:91-6.

24. Pintado C, de Miguel A, Acevedo O, et al. Bactericidal effect of saffron (Crocus sativus L.) on Salmonella enterica during storage. Food Control 2011;22:63842.

25. Cosano I, Pintado C, Acevedo O, et al. Microbiological quality of Saffron from the main producer countries. J Food Prot 2009;72:2217-20.

26. Fernandez J. Genetic resources of saffron and allies (Crocus spp.). Acta Hortic 2007;739:167-85.

27. Jahan M, Jahani M. The effects of chemical and organic fertilizers on saffron flowering. Acta Hortic 2007;739:81-6.

28. Salwee Y, Nehvi F. Saffron as a valuable spice: a comprehensive review. Afri J Agric Res 2011;8:234-42.

29. Agayev YM, Shakib AM, Soheilivand S, Fathi M. Breeding of saffron (Crocus sativus): possibilities and problems. Leuven, Belgium: International Society for Horticultural Science (ISHS); 2007.

30. Himeno H, Sana K. Synthesis of crocin, picocrocin and safranal by saffron stigma-like structure proliferated in vitro. Agric Biol Chem 1987;51:2395-400.

31. Busconi M, Colli L, Sánchez R, et al. AFLP and MS-AFLP Analysis of the Variation within Saffron Crocus (Crocus sativus L.). Germplasm PLoS ONE 2015;10:e0123434.

32. Hosseinzadeh Gonabad Y. Caratterizzazione morfologica e molecolare dello zafferano (Crocus sativus L.) iraniano (Khorasan). Università degli Studi di Perugia: $\mathrm{PhD}$ Thesis; 2013.

33. Gresta F, Lombardo G, Ruberto G, Siracusa L. Saffron, an alternative crop for sustainable agricultural systems: a review. Agron Sustainable Devel 2008;28:95-112.

34. Ordoudi SA, Tsimidou MZ. Saffron quality: effect of agricultural practices, processing and storage. In: Dris R, Jain $\mathrm{SM}$, eds. Production Practices and Quality Assessment of Food Crops, Vol 1: Preharvest Practice. Dordrecht: Springer Netherlands; 2004. pp 209-
260.

35. Siracusa L, Gresta F, Avola G, et al. Influence of environmental factors and corms provenience on yield and apocarotenoid profiles of saffron (Crocus sativus L.). J Food Comp Anal 2010;23:394-400.

36. Alavi-Kia S, Mohammadi S, Aharizad S, Moghaddam M. Analysis of genetic diversity and phylogenetic relationships in Crocus genus of Iran using interretrotransposon amplified polymorphism. Biotechnol Biotec Eq 2008;22:795-800.

37. Grilli Caiola M, Di Somma D, Lauretti P. Comparative study of pollen and pistil of Crocus sativus L. (Iridaceae) and its allied species. Ann Bot 2001;1:7382

38. Grilli Caiola M, Zaier R. RAPD analysis in Crocus sativus L. accessions and related Crocus species. Biol Plant 2004;48:375-80.

39. Namayandeha A, Nematib Z, Kamelmaneshc M, et al. Genetic relationships among species of Iranian crocus (Crocus spp.). Crop Breed J 2012;3:61-7.

40. Singh A, Smartt J, Simpson C, Raina S. Genetic variation via molecular polymorphism in groundnut, Arachis hypogaea L. Genet Resour Crop Ev 998;45:119-26.

41. Mariano V, McCrindle CM, CenciGoga B, Picard JA. Case-control study to determine whether river water can spread tetracycline resistance to unexposed impala (Aepyceros melampus) in Kruger National Park (South Africa). Appl Environ Microbiol 2009;75:1138.

42. Chemical disinfectants and antiseptics. Quantitative suspension test for the evaluation of basic bactericidal activity of chemical disinfectants and antiseptics. Test Method and Requirements (phase 1); 2006.

43. Iulietto MF, Sechi P, Borgogni E, Cenci-Goga BT. Meat spoilage: a critical review of a neglected alteration due to ropy slime producing bacteria. Ital J Animal Sci 2015;14:4011. 